\title{
Del árabe al hebreo. \\ El nacimiento de la ginecología hebrea medieval y el Canon de la medicina de Ibn Sīnā*
}

\author{
Carmen Caballero Navas** \\ Universidad de Granada
}

ORCID ID: https://orcid.org/0000-0003-1677-1427

Este artículo pretende demostrar que el Zijrón ha-holayim ha-hovim be-klé ha-herayón (Memoria de las enfermedades que afectan a los órganos de la reproducción) -un breve tratado anónimo dedicado a las enfermedades de los órganos genitales de hombres y mujeres, escrito en hebreo en Castilla a fines del siglo XII o principios del XIII- es un epítome de los funūn 20 y 21 del Libro III del Canon de la medicina de Ibn Sīnā, realizado directamente desde la lengua árabe varias décadas antes de su primera traducción conocida al hebreo. Para ello se ha llevado a cabo el cotejo preliminar del único manuscrito en que se conserva el tratado y varios testigos en hebreo y latín del Canon, y se ha analizado su producción en el contexto de los movimientos de traducción, apropiación y difusión de conocimiento médico de la Castilla multicultural y plurilingüe de los siglos XII al XIV. También se ha examinado el lugar que ocupa el Zijrón en el corpus hebreo dedicado al cuidado de la salud femenina, y se ha indagado sobre su difusión en el siglo xv, en el marco del nuevo interés que despertó la ginecología entre los autores y consumidores de literatura médica de la Europa bajomedieval.

Palabras Clave: Medicina; corpus hebreo; salud femenina; movimientos de traducción; tradición latina; tradición árabe.

From Arabic into Hebrew. The Birth of Medieval Hebrew Gynaecology and IBN SīnĀ's CANON OF MEDICINE.- The aim of this essay is to show that the Zikhron haholayim ha-hovim be-klei ha-herayon (An account of the diseases of the organs of pregnancy) - a short Hebrew treatise on the conditions of male and female sexual organs, written in Castile at the turn of the 12th century- is an epitome of funün 20 and 21 of

* La investigación de este artículo ha sido realizada en el marco del Proyecto de Investigación «Lengua y Literatura del Judaísmo Rabínico y Medieval» (FFI201678171-P), financiado por el Ministerio de Ciencia, Innovación y Universidades, y Fondos FEDER. Agradezco los comentarios de dos evaluadores anónimos que me han ayudado a mejorar este artículo.

** carmenca@ugr.es

Copyright: (C) 2019 CSIC. Este es un artículo de acceso abierto distribuido bajo los términos de la licencia de uso y distribución Creative Commons Reconocimiento 4.0 Internacional (CC BY 4.0). 
Book III from Ibn Sīnā's Canon of Medicine, drawn directly from Arabic some decades prior to the first known Hebrew translation. With this in mind, the only manuscript copy from the Hebrew treatise so far identified and several Hebrew and Latin witnesses of the Canon have been collated. Moreover, its production has been analyzed in the context of the movements of translation, appropriation and transmission of medical knowledge that occurred in multicultural and multilingual Castile between the 12th and the 14th centuries. The essay also examines the position of the Zikhron within the Hebrew corpus of literature on women's health care, as well as its late circulation in the 15th century, prompted by the new interest on gynaecology shown by male medical authors and their audiences.

KeYwords: medicine; Hebrew corpus; Women's healthcare; Translation movements; Latin tradition; Arabic tradition.

El Zijrón ha-holayim ha-hovim be-klé ha-herayón, o Memoria de las enfermedades que afectan a los órganos de la reproducción, es un breve tratado anónimo escrito en hebreo, dedicado a las enfermedades de los órganos sexuales de hombres y mujeres, que se conserva en una única copia manuscrita del siglo xv de origen sefardí ${ }^{1}$. De acuerdo con Ron Barkai, que editó y tradujo el tratado al inglés en 1998 junto con otras cinco obras ginecológicas escritas o traducidas al hebreo durante la Edad $\mathrm{Media}^{2}$, éste parece haber sido compuesto entre la segunda mitad del siglo XII y principios del siglo XIII en Castilla. De confirmarse su hipótesis, ello lo convertiría en una de las primeras obras ginecológicas (y médicas) compuestas originalmente en hebreo, al haber sido producida

${ }^{1}$ Londres, Wellcome Institute, MS A37 (Montefiore 440) fols. 15v-24r [de aquí en adelante MS Wellcome]; vid. Moritz SteInsCHNEIDER, «Medizinische Handschriften im Besitz des Herrn Halberstam», Magazin für die Wissenschaft des Judenthums 10 (1883) págs. 101-112: 103; Hartwig HiRschFeld, Descriptive Catalogue of the Hebrew Manuscripts of the Montefiore Library (Londres, 1904) pág. 132, en el que se refiere al tratado como "On diseases of the womb», y Ron BARKAI, A History of Jewish Gynaecological Texts in the Middle Ages (Leiden: Brill, 1998) págs. 68-76.

2 BARKAI, A History of Jewish Gynaecological Texts, que ofrece la edición y traducción inglesa en las págs. 109-144. Es importe señalar que, de acuerdo con la copia manuscrita, el tratado termina en las primeras líneas del fol. 24r. A continuación, el compilador o copista del códice ha añadido una serie de recetas de otra procedencia (fols. 24r-24v), así como un fragmento sobre los síntomas del exceso de humores en el útero (fols. 24v:21-25r). Barkai incluyó este último fragmento en su edición por considerarlo de interés (págs. 120-121 y 143-144, respectivamente). 
durante la primera etapa tras la inauguración del corpus médico hebreo a fines del siglo XII.

Si bien la argumentación de Barkai con respecto a la fecha y lugar de composición, que se expondrá más adelante, es muy sólida y convincente, mi trabajo en curso sobre el corpus textual hebreo dedicado a la salud femenina ha dado lugar a una nueva propuesta en cuanto a la originalidad y autoría de la obra. Las similitudes encontradas entre algunos pasajes del Zijrón y fragmentos del Libro III del Kitāb al-Qānūn fi al-țibb (Canon de la Medicina) de Ibn Sīnā (980-1038), junto a la influencia del árabe en la lengua hebrea en que está escrito, sugieren que el autor judío tuvo acceso al Canon en árabe y pudo extraer directamente de él dichos pasajes. Es más, los resultados de mi estudio me llevan a sugerir que este breve tratado constituye la primera versión hebrea, adaptada y abreviada - por el momento no podemos saber si la que se conserva es la extensión original del tratado o era más extenso en su origen-, de secciones del Libro III del Canon, lo que adelantaría la circulación en lengua hebrea de partes de la célebre obra en varias décadas ${ }^{3}$.

En lo que sigue, presento los resultados de un estudio preliminar en el que se han analizado el tratado hebreo y su relación con el Canon de Ibn Sīnā, así como la acogida que este pudo tener entre las comunidades

${ }^{3}$ Me he referido a algunas de las similitudes encontradas en publicaciones anteriores, aunque en ninguna de ellas se ha formulado la hipótesis sobre que el Zijrón fuera una sinopsis hebrea de parte del Libro III del Canon de Ibn Sīnā; vid. Carmen CabalLERO NAVAS, «Maimonides' Contribution to Women's Health Care and His Influence on the Hebrew Gynaecological Corpus», en Traditions of Maimonideanism, ed. Carlos Fraenkel (Leiden: Brill, 2009) págs. 33-50: 40 y 46-47; «Medicine among Medieval Jews: The Science, the Art, and the Practice», en Science in Medieval Jewish Cultures, ed. Gad Freudenthal (Cambridge: Cambridge University Press, 2011) págs. 320-342: 334; «Maimonides and his Practice of Gynaecology», en Moses Maimonides and His Practice of Medicine, eds. Kenneth E. Collins, Samuel S. Kottek y Fred Rosner (Haifa: Maimonides Research Institute, 2013) págs. 61-84: 62, y «She Will Give Birth Immediately. Pregnancy and Childbirth in Medieval Hebrew Medical Texts Produced in the Mediterranean West», Dynamis 34:2 (2014) págs. 377-401: 392. Por otro lado, he presentado sucesivamente parte de los resultados de mi investigación en varios congresos internacionales: Medical Texts in Hebrew Contexts - Jewish Physicians and the Dynamics of Cultural Transfer in Pre-Modern Europe (Jerusalén 2013), International Medieval Congress (Leeds 2016) y XIth Congress of the European Association for Jewish Studies (Cracovia 2018). 
judías medievales; también se ha contextualizado su producción en el marco de los movimientos de traducción de la Castilla multicultural y plurilingüe del paso del siglo XII al XIII y se ha examinado su lugar en el corpus hebreo dedicado al cuidado de la salud femenina. Por último, se ha indagado sobre su difusión en el siglo xv, en el marco del nuevo interés que despertó la ginecología entre los autores y consumidores de literatura médica de la Europa tardomedieval.

\section{UN TRATADO SINGULAR EN LOS INICIOS DE LA MEDICINA Y LA GINECOLOGÍA HEBREAS}

Excepto por un número muy reducido de ejemplos, no se plasmaron por escrito ni circularon en hebreo textos de carácter científico hasta la primera mitad del siglo XII ${ }^{4}$. De hecho, la inauguración del corpus hebreo de medicina no se producirá hasta los últimos años del siglo, cuando Doeg ha-Edomí -seudónimo bajo el que se esconde un traductor activo en Provenza- vierta veinticuatro obras médicas del latín al hebreo entre 1197 y $1199^{5}$. Tres de ellas son tratados ginecológicos: Séfer ha-tolédet (Libro de la generación), traducción de la Gynaecia de Muscio (siglos V-VI); ${ }^{6}$ Séfer ha-em el-Galinus hu ha-nicra Guíneas (Libro del útero de Galeno llamado Gynaecia), traducción del tratado De passionibus

4 Tzvi Langermann, The Jews and the Sciences in the Middle Ages (Ashgate: Aldershot, 1999); Gad Freudenthal, «Arabic and Latin Cultures as Resources for the Hebrew Translation Movement», en Science in Medieval Jewish Cultures, ed. Gad Freudenthal (Cambridge: Cambridge University Press, 2011) págs. 74-105.

5 Moritz Steinschneider, Die Hebräischen Übersetzungen des Mittelalters und die Juden als Dolmetscher (Berlin: Kommissionsverlag des Bibliographischen Bureaus, 1893) págs. 711-714, y «Haqdamat ha-ma'atîq bi-ketab yad Paris 1190», $M a-$ gazin für die Wissenschaft des Judenthums 15 (1888) págs. 197 y 6-14 (sección en hebreo); BarkaI, A History of Jewish Gynaecological Texts, págs. 20-34; Gad FreuDenthal, "The Father of the Latin-into-Hebrew Translations: 'Do'eg the Edomite', the Twelfth Century Repentant Convert», en Latin-into-Hebrew: Texts and Studies, eds. Ressiane Fontaine and Gad Freudenthal, vol. 1 (Leiden: Brill, 2013) págs. 105120.

${ }^{6}$ Ron BARKaI, Les infortunes de Dinah, ou la gynécologie juive au Moyen Âge (Paris: Cerf, 1991; traducción al francés de Michel Garel). 
mulierum, versión $\mathrm{B}$ (siglo xI); ${ }^{7}$ y la primera traducción a una lengua distinta del latín de parte del famoso compendio medieval sobre salud femenina atribuido a Trota de Salerno; en concreto, de dos de los tres textos que lo formaban, Liber de sinthomatibus mulierum y De ornatu mulierum $^{8}$. Significativamente, se ha preservado una copia manuscrita, aparentemente fragmentaria, de esta traducción en el mismo códice en que el que se conserva la única copia del Zijrón ${ }^{9}$. A ello volveremos más tarde.

La ginecología se convierte de esta forma en un género de la literatura médica en hebreo que nace bajo la influencia de la tradición médica latina y seguirá en gran medida las corrientes contemporáneas que adopten los autores y filósofos cristianos. A pesar de ello, los textos que irán formando el corpus a lo largo de la Edad Media son el resultado de la armonización de diversas tradiciones médicas medievales. En ellos se puede observar el influjo de distintas teorías que circularon por la extensa época en que fueron escritos y la huella de nociones derivadas de las tradiciones médicas greco-latina, árabe y cristiana, junto con la impronta de prácticas locales (femeninas) ${ }^{10}$. Las diversidad de rutas por las que las ideas y conceptos sobre anatomía, fisiología y salud femenina llegan al corpus hebreo es patente desde el principio de su fundación. Sin ir más lejos, casi contemporáneamente con las traducciones latinas de Doeg ha-Edomí en Provenza, otros dos tratados hebreos sobre salud femenina fueron compuestos y circularon en la Península Ibérica en la

${ }^{7}$ Editada y traducida al inglés en BARKAI, A History of Jewish Gynaecological Texts, págs. 145-180.

${ }^{8}$ Para la edición y traducción de las dos versiones preservadas, véanse BARKAI, $A$ History of Jewish Gynaecological Texts, págs. 181-191, y Carmen Caballero Navas, «Algunos 'secretos de mujeres' revelados. El Še'ar yašub y la recepción y transmisión del Trotula en hebreo», Miscelánea de Estudios Árabes y Hebraicos, Sección Hebreo 55 (2006) págs. 381-425. Sobre la obra latina aludida, veáse más adelante nota 59.

9 Séfer ha-em el-Galinus hu ha-nicrá Guíneas ocupa los fols. 25r-53r, y Séfer hatolédet los fols. $53 \mathrm{v}-62 \mathrm{v}$. El cuarto tratado del códice, sobre las hemorroides, ocupa los fols. $1 \mathrm{r}-15 \mathrm{r}$.

10 Barkai, A History of Jewish Gynaecological Texts; Carmen Caballero Navas, «The Genesis of Medieval Hebrew Gynaecology: A Preliminary Assessment», en Defining Jewish Medicine. Transfer of Medical Knowledge in Jewish Cultures and Traditions, ed. Lennart LehmHaus (Wiesbaden: Harrassowitz Verlag, en prensa). 
encrucijada de los siglos XII y XIII: Terufot la-herayón ha-nicrá maguén ha-róś (Medicamentos para el embarazo, llamado «Escudo de la cabeza»), al parecer escrito en árabe por Šešet Benveniste, dirigente de la comunidad judía de Barcelona y médico de los reyes de Aragón Alfons II y Pere II, y traducido al hebreo por Yehudah al-Harizi (m. 1235) ${ }^{11}$, y la obra que nos ocupa.

El Zijrón ha-holayim ha-hovim be-klé ha-herayón, de acuerdo al título que le da el único manuscrito en el que se conserva, está dividido en dos secciones ${ }^{12}$. La primera está dedicada a enfermedades y afecciones sexuales masculinas, tales como la ausencia o el exceso de deseo sexual, la erección prolongada sin deseo sexual, los apostemas, las inflamaciones y las hernias en distintas partes de los órganos genitales de los hombres. En la segunda, introducida mediante la frase en letra cuadrada de mayor tamaño «Memoria de las enfermedades que se reproducen en el útero» ${ }^{13}$, el autor hace un recorrido por una serie de incidencias y dolencias relacionadas estrechamente con el ciclo de vida femenino, explica su etiología, describe los síntomas y ofrece tratamientos terapéuticos. Todo ello, de acuerdo con la teoría hipocrático-galénica de los humores: sobre la esterilidad y lo que impide el embarazo, la mola, el parto detenido u obstruido, la sofocación uterina, la menstruación excesiva, y la retención y disminución de sangre menstrual.

De acuerdo con Ron Barkai, el desconocido autor podría haber sido un judío emigrado a territorios cristianos de la Península Ibérica, posiblemente Castilla, desde zonas bajo dominio islámico. Basa su hipótesis en el impacto evidente de la lengua árabe en la terminología, sintaxis y estilo del texto. El peso del árabe en la obra es tal que llevó a Steinschneider a sugerir que podría tratarse de una traducción desde dicha len-

11 BarkaI, A History of Jewish Gynaecological Texts, págs. 83-86 (estudio) y 192211 (edición y traducción al inglés). De acuerdo con el catálogo en línea del Instituto de Manuscritos Microfilmados de la Biblioteca Nacional y Universitaria de Israel, en Jerusalén, el título del tratado (microfilm F19956) es Terufot u-mercahot la-mahalot našim (Medicamentos y pócimas para las enfermedades de las mujeres).

12 MS Wellcome, fols. 15v-19v y 19v-24r, respectivamente. BARKAI, A History of Jewish Gynaecological Texts, págs. 109-114 y 114-120 (hebreo), 121-131 y 131-143 (traducción inglesa).

13 זכון החליים המתחדשים ברחם. MS Wellcome, fol. 19v. BarkaI, A History of Jewish Gynaecological Texts, págs. 114 (hebreo) y 131 (traducción inglesa). 
gua ${ }^{14}$. El autor no duda en recurrir a expresiones gramaticales, calcos semánticos e incluso palabras transliteradas del árabe en grafía hebrea. Por ejemplo, los nombres de algunas enfermedades, como נזף (menstruación excesiva), צר רחא (mola); u otros muchos términos como אל אבהל (sabina), דלט (humor), דהן (aceite) מעגון (electuario) ${ }^{15}$.

Barkai también señala que, además del árabe, cuyo uso -nos recuerda- estaba reconocido en Castilla, el autor recurre a algunos términos del romance castellano ${ }^{16}$. En mi opinión, si bien es cierto que el grado de homogeneización lingüística que se puede observar en el uso de la terminología científica y técnica en diversas zonas de los territorios cristianos de la Península Ibérica y el Sur europeo en esta época dificulta la identificación de la lengua vernácula que se esconde tras los términos romanceados de la obra, algunos usos parecen indicar que efectivamente podría tratarse del castellano, aunque también se identifican grafías que podrían corresponderse con vocablos en catalán o aragonés. Entre las

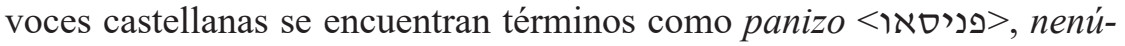

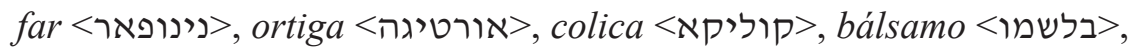
sacaviento > גירא שוליש>> > o girasoles, entre otros ${ }^{17}$. Por otro lado, Barkai menciona el empleo de expresiones talmúdicas, así como de terminología científica expresada en un hebreo anterior al léxico científico creado por los traductores de los siglos XIII y XIV, para proponer una fecha temprana de composición ${ }^{18}$.

14 Steinschneider, «Medizinische Handschriften», pág. 103.

15 BarkaI, A History of Jewish Gynaecological Texts, págs. 69, y 118, 117, 115, 16, 111, 112 y 109, respectivamente, de la edición hebrea. Véase también MS Wellcome, fols. 22v, 21v, 20r, 20v, 17r, 18r y 15v, repectivamente.

16 Barkai, A History of Jewish Gynaecological Texts, págs. 69-70.

17 MS Wellcome, fols. 16r-v, 19r y 20r, respectivamente; $c f$. BARKAI, A History of Jewish Gynaecological Texts, págs. 110, 111, 114 y 115. Sobre los criterios para identificar palabras castellanas en caracteres hebreos, véase Gerrit Bos y Guido Mensching, "A 15th Century Medico-Botanical Synonym List (Ibero-Romance-Arabic) in Hebrew Characters»,Panace@ VII:24 (2006) págs. 261-268: 263-265. Sobre el uso y significado en la medicina castellana medieval de los términos referidos arriba, véase María Teresa Herrera, Diccionario español de textos médicos antiguos. 2 vols. (Madrid, Arco/Libros, 1996) págs. 1169, 1104, 1154, 336, 277 y 1410, respectivamente. En estos momentos me encuentro realizando un estudio en profundidad de la terminología usada en el tratado, sobre la que hay señalar su marcado carácter plurilingüe.

18 Barkai, A History of Jewish Gynaecological Texts, pág. 70. 
Junto a todo ello, el tratado también presenta otras características distintivas que lo conectan a la tradición médica árabe, como la selección de contenidos y el propio formato en el que se organizan y presentan. Aunque, a diferencia de la medicina de tradición latina, la medicina árabe no desarrolló un género independiente dedicado a la ginecología, las enciclopedias médicas reunían abundante material sobre fisiología, salud y enfermedad femeninas basado en las teorías ginecológicas de la antigüedad greco-latina y bizantina ${ }^{19}$. Algunos autores y sus secciones sobre enfermedades femeninas disfrutaron de gran popularidad entre sus contemporáneos y fueron transmitidos a tradiciones médicas posteriores gracias a sus traducciones a otras lenguas medievales. Obras como el Kitāb kāmil aș-șinā'a aț-tibbìya (El Libro perfecto del arte médico) de al-Maŷūsī (ca. 925-994), o el especialmente importante para la ginecología hebrea Zād al-musāfir wa-qūt al-hādir (Provisiones para el viajero y nutrición para el sedentario) de Ibn al-Ŷazzār (895-979), que organizan sus contenidos a capite ad calcem, dedicaron secciones a las enfermedades que afectan a los órganos sexuales de hombres y mujeres. Además de la anatomía de los órganos de la reproducción que incluye al-Maŷūs̄̄ en el primer libro (sobre los principios teóricos) de su enciclopedia médica, dedica el capítulo 8 del segundo libro (práctica) a la terapia de las enfermedades que afectan a los órganos de la reproducción ${ }^{20}$. Por su parte, el libro sexto del Zād al-musāfir se organiza en dos apartados

19 Monica Green, «History of Science», Encyclopedia of Women and Islamic Cultures. Methologies, Paradigms and Sources (Leiden: Brill, 2003) vol. I, págs. 358-361. Sobre la producción y difusión de enciclopedias médicas en el Islam, véase Danielle JACQUART y Françoise MiCHEAU, La médecine arabe et l'occident médiéval (Paris: Edicions Maisonneuve et Larose, 1996) págs. 55-86.

${ }^{20}$ La enciclopedia de al-Maŷūsī, conocida en Occidente como Pantegni, fue traducida al latín por Constantino el Africano a fines del siglo XI en Montecasino, y un siglo más tarde del latín al hebreo por Doeg ha-Edomí con el título Séfer male' mahziq; vid. Charles BurnetT y Danielle JACQuART, (eds.), Constantine the African and 'Alī ibn al-'Abbās al-Mă̆ūsī. The "Pantegni" and Related Texts. Leiden, Brill, 2004; especialmente, Monica Green, «The re-creation of Pantegini, Practica, book VIII», págs. 121160, y Ron BarkaI, «The Judeo-Arabic and Hebrew versions of the Kitāb kāmil așșinā'a», págs. 57-70. Sobre la traducción hebrea, véanse también STEINSCHNEIDER, «Haqdamat», pág. 7, y Freudenthal, «The Father of the Latin-into-Hebrew Translations», pág. 119. 
dedicados a enfermedades de los órganos sexuales masculinos y femeninos, en un formato muy similar al del Zijrón ${ }^{21}$.

Sin embargo, el Zād al-musāfir no es la única obra árabe que sigue ese modelo. El Kitāb al-Qānūn fì al-țibb o Canon de la medicina, obra principal de Ibn Sīnā y quizá la de mayor influencia en la tradición médica occidental, completada en 1025 y dividida en cinco libros, también incluye un apartado de contenidos y organización similares. El Libro III, que expone sistemáticamente la función y enfermedad de cada órgano del cuerpo de la cabeza a los pies, se divide en veintidós funūn (heb. ofanim) o tratados, que a su vez se organizan en maqālāt (heb. maamarim o limudim) o discursos, que se subdividen en fușūl (heb. peraquim) o capítulos. Los funūn 20 y 21 del libro III tratan de las enfermedades de los órganos reproductivos de los hombres y de las mujeres, respectivamente. Tras la identificación -de forma casi fortuita, cuando revisaba la traducción al hebreo del Canon realizada por Natán ha-Meatí hacia 1279- de pasajes paralelos entre el fann (sing. de funūn) 21 del Libro III y el Zijrón, comencé a considerar al primero como una fuente plausible del segundo ${ }^{22}$. Este es el punto de partida de esta investigación, que pasa necesariamente por considerar la relación que mantuvieron los intelectuales de las sociedades judías medievales con el Canon de la medicina.

${ }^{21}$ Gerrit Bos, Ibn Al-Jazzār on Sexual Diseases and Their Treatment. A critical edition of Zād al-musāfir wa-qūt al hạdir (Provisions for the Traveller and Nourishment for the Sedentary) (London-New York: Kegan Paul International, 1997). La obra fue traducida al latín por Constantino el Africano como Viaticum peregrinantis y al hebreo por Doeg ha-Edomí como Séfer yair nativ: vid. STENSCHNEIDER, Die hebräischen Übersetzungen, págs. 703-704; Steinschneider, «Haqdamat», pág. 7, y Freudenthal, «The Father of the Latin-into-Hebrew Translations», pág. 119. Aunque la traducción de Doeg fue la que tuvo mayor influencia en tratados hebreos posteriores dedicados a salud femenina, Zād al-musāfir fue traducido en otras dos ocasiones al hebreo, por Moses Ibn Tibbon desde el árabe en 1259, y una vez más desde el latín por Abraham ben Isaac en el siglo Xv; vid. StenschneIDer, Die hebräischen Übersetzungen, págs. 703-704; Carmen Caballero Navas, The Book of Women's Love and Jewish Medieval Medical Literature on Women. Sefer ahavat nashim (London: Kegan Paul, 2004) pág. 29, y Mauro ZonTA, «Medieval Hebrew Translations of Philosophical and Scientific Texts. A Chronological Table», en Science in Medieval Jewish Cultures, ed. Gad Freudenthal (Cambridge: Cambridge University Press, 2011) págs. 17-73: 23, 32 y 99.

22 Caballero Navas, «Maimonides' Contribution to Women's Health Care», págs. 40 y $46-47$.

SEFARAD, vol. 79:1, enero-junio 2019, págs. 89-122. ISSN: 0037-0894. https://doi.org/10.3989/sefarad.019-002 


\section{EL ZiJRoN Y LA ADMIRACIÓN JUDÍA POR EL CANON DE LA MEDICINA}

El Canon de la medicina fue recibido con entusiasmo por los intelectuales de las culturas judías de la Edad Media, convirtiéndose en la obra médica que gozó de mayor difusión entre ellas tanto en árabe o judeo-árabe como en sus traducciones hebreas. No debemos perder de vista que antes, durante y después de la inauguración del corpus textual hebreo de medicina a finales del siglo xir y hasta el final de la Edad Media, los judíos tuvieron acceso a la obra en (judeo)árabe, no solo en territorios bajo dominio islámico, sino también en la Europa cristiana. Particularmente en la Península Ibérica, donde los judíos arabófonos del lado cristiano de la frontera pudieron leerlo y usarlo durante siglos en lengua árabe, al igual que hicieran con muchas otras obras, como demuestra el hecho de que una proporción considerable de los manuscritos médicos árabes de origen hispano conservados pertenecieron o fueron copiados por judíos ${ }^{23}$. Cuando a finales del siglo XIII el Canon sea traducido por primera vez al hebreo, lo será desde el árabe, como también lo serán las siguientes traducciones de la obra.

Natán ha-Meatí completó la primera traducción de toda la obra en 1279 en Roma. Alrededor de la misma fecha y en el mismo lugar, Zerahia ben Yiṣhac Hen tradujo los libros I y II. Un siglo más tarde, Josef ben Yošúa Ibn Vives ha-Lorquí tradujo el Libro I y dos tratados del Libro II en la Península Ibérica. Contando las traducciones parciales anónimas que se han conservado, algunos estudiosos estiman que el Canon fue traducido al hebreo en al menos siete ocasiones. De las distintas versiones se conservan más de 150 copias manuscritas parciales y completas, a las que hay que sumar alrededor de una treintena de comentarios ${ }^{24}$. Finalmente, la obra fue impresa por Azriel ben Josef en

${ }^{23}$ Pieter Sj. van Koningsveld, «Andalusian Arabic Manuscripts from Medieval Christian Spain: Some Supplementary Notes», Festgabe für H. R. Singer (Frankfurt, 1991) págs. 811-823 y «Andalusian-Arabic Manuscripts from Christian Spain: A Comparative, Intercultural, Approach», Israel Oriental Studies 12 (1992) págs. 75-110: 89-90; en las págs. 100-103 se identifican dos fragmentos del Canon entre el grupo de manuscritos.

${ }^{24}$ Benjamin RichleR, «Manuscripts of Avicenna's Kanon in Hebrew Translations, a Revised and Up-to-date List», Korot 8 (1982) págs. 145-168; Lola FerRe, «Tras las 
Napoles, en1491-1492, a partir de las versiones de Natán ha-Meatí y de Josef ben Yošúa Ibn Vives ha-Lorquí. La obra impresa constituye el más extenso de los 139 incunables hebreos y el único de medicina, y de él se conservan unas 51 copias completas y fragmentarias ${ }^{25}$.

A diferencia de lo que ocurre con las versiones hebreas, cuya difusión es relativamente sencilla de evaluar gracias a la identificación y catalogación de los manuscritos conservados, conocer su circulación en árabe entre las comunidades judías arabófonas se convierte en una tarea ardua cuando no hay indicios que identifiquen su procedencia judía o su uso por parte de judíos. Por el contrario, la conservación de manuscritos en judeo-árabe, o con anotaciones marginales en hebreo ${ }^{26}$, nos permite confirmar el aprecio del que gozó entre los intelectuales de dichas comunidades, e incluso esbozar una estimación gracias, entre otros, a los resultados de los estudios realizados en los documentos de la impresionante colección de la Genizah del Cairo ${ }^{27}$. En cualquier

huellas del Canon hebraico», en Avicena, Canon medicinae: estudio y edición facsímil del ms. 2197 de la Biblioteca Universitaria de Bolonia. Libro de estudios (Madrid: AyN Ediciones, 2002) págs. 244-287; Gad Freudenthal y Mauro ZontA, «Avicenna among Medieval Jews. The Reception of Avicenna's Philosophical, Scientific and Medical Writings in Jewish Cultures, East and West», Arabic Sciences and Philosophy 22:2 (2012) págs. 217-287: 270-271.

25 Carmen Caballero Navas, «Medical Knowledge in Hebrew: Manuscripts and Early Printed Books» Medicina nei Secoli 17:2 (2005) págs. 275-292: 285-286; FreUDENTHal y Zonta, «Avicenna among Medieval Jews», pág. 271.

26 Tzvi Langermann identificó una lista de manuscritos judeo-árabes de autores no judíos que incluía 18 copias del Canon. La lista fue ampliada hasta 22 copias por Freudenthal y Zonta; vid. Tzvi Langermann, «Arabic Writings in Hebrew Manuscripts: A Preliminary Relisting», Arabic Sciences and Philosophy 6 (1996) págs. 137-160 y «Transcriptions of Arabic Treatises into the Hebrew Alphabet: An Underappreciated Mode of Transmission», en Tradition, Transmission, Transformation, eds. F. Jamil RageP y Sally P. RAgeP (Leiden: Brill, 1996) págs. 247-260, y Freudenthal y ZonTA, «Avicenna among Medieval Jews», págs. 234-236.

27 Haskell D. IsAACS y Colin BAKER, Medical and Para-Medical Manuscripts in the Cambridge Genizah Collections (Cambridge: Cambridge University Press, 1994); Friedrich Niessen y Efraim Lev, «Addenda to Isaac's Medical and Para-Medical Manuscripts in the Cambridge Genizah Collections Together with the Edition of Two Medical Documents T-S 12.33 and T-S NS 297.56», Hebrew Union College Annual 77 (2006) págs. 131-165. Por último, Renate Smithius y Sagit Butbul («Appendix - Avicenna in The Cairo Geniza», en Freudenthal y Zonta, «Avicenna among Medieval Jews», 
caso, fuera leído y estudiado en árabe o en hebreo, el Canon y su autor se habían convertido en una autoridad incuestionable para los autores médicos judíos hacia mediados de la Edad Media, de forma que numerosos textos médicos hebreos, incluidos los dedicados al cuidado de la salud femenina, los citan como fuente de innumerables recetas, remedios, procedimientos y teorías médicas, aunque a menudo llegaran a ellos de forma indirecta ${ }^{28}$. Este reconocimiento y admiración corroboran las palabras que escribiera Nancy Siriasi hace ya tres décadas, «the most extensive use of the Canon outside the universities in western Europe during the Middle Ages was unquestionably by Jewish physicians» ${ }^{29}$. Pero eso sería un poco más adelante. A fines del siglo XII o principios del XIII, solo los judíos arabófonos habían tenido y tenían acceso al Canon.

\section{ESTUDIO COMPARATIVO PRELIMINAR}

Una vez identificados los funūn del Canon de la medicina que tanto por su temática como por los pasajes paralelos encontrados guardan una estrecha relación con el Zijrón, se inició un estudio preliminar que consistió en el cotejo de ambas obras. Para el cotejo, se ha utilizado el único manuscrito en el que se conserva el tratado hebreo ${ }^{30}$, así como la edición moderna de Ron Barkai ${ }^{31}$. En cuanto a las versiones hebreas de Canon, teniendo en cuenta que solo Natán ha-Meatí y un traductor desconocido

págs. 284-286) han identificado entre las distintas colecciones de la Genizah del Cairo seis fragmentos del Canon en árabe con grafía hebrea, siete en hebreo y 28 en árabe.

28 Por ejemplo, Séfer ahavat našim (Libro de amor de mujeres), conservado en un manuscrito del siglo xv, cita a Ibn Sīnā en diez ocasiones como fuente de remedios de una gran variedad de dolencias como dolor de dientes, mal olor corporal, embarazo, prolapso de útero, fertilidad, parto, hemorragia menstrual y anticoncepción. La mayoría de los temas son tratados en el Canon, aunque no se ha podido demostrar que los fragmentos hayan sido tomados directamente de allí; vid. Florencia, Biblioteca MediceaLaurenziana, MS Pluteo 44.22/7, fols. 73v, 74v, 77v, 79v, 54v, 55v-56r, 57r y 58r, y Caballero Navas, The Book of Women's Love, págs. 135, 139, 151, 157, 163 y 167.

29 Nancy SirAIsI, Avicenna in Renaissance Italy. The Canon and Medical Teaching in Italian Universities after 1500 (Princeton: Princeton University press, 1987) pág. 48.

${ }^{30}$ MS Wellcome, fols. 15v-24r.

31 Véase, arriba, nota 2. 
tradujeron el Libro III, se han usado dos de los manuscritos que conservan la versión de Natán ha-Meatín ${ }^{32}$ y un manuscrito del siglo XIV que conserva la versión anónima ${ }^{33}$. Asimismo, se han consultado la edición latina de 1608 (Venecia), basada en la traducción de Gerardo de Cremona (ca. 1087) y la primera edición del árabe de 1593 (Roma) ${ }^{34}$. De esta última solo se ha usado el extenso y detallado índice con el fin de cotejar los contenidos con el de las traducciones hebreas y latina. Se prevé profundizar en la comparación con la versión latina de Gerardo de Cremona pero, sobre todo, en la correspondencia con algunas versiones árabes, en una segunda fase del proyecto.

El cotejo de los textos reveló que el Zijrón, tal y como lo conocemos hoy día, es un epítome de los funūn 20 y 21 del Libro III del Canon de la medicina, mediante el que el autor -al que parece ahora más acertado llamar compendiador- o un copista posterior, adaptó considerablemente los contenidos al omitir capítulos y temas, y abreviar significativamente la extensión. La lectura del tratado hebreo evidencia que se ha llevado a cabo una selección de los cuestiones que interesaban al compendiador o a sus lectores potenciales. Curiosamente, mientras que en la obra original árabe y en las versiones hebreas la extensión del fann 21 es considerablemente mayor a la del fann 20, en el Zijrón la diferencia en extensión disminuye, debido a que la labor de síntesis ha sido mayor en la segunda sección del tratado ${ }^{35}$. La primera sección del tratado

32 Munich, Bayerische Staatsbibliothek, MS 87 (en adelante, MS Munich) fols. 275v-293v; Bolonia, University Library, MS 2197 (en adelante, MS Bolonia). Aparte de tres copias completas de la traducción de Natán ha-Meatí, se conservan 21 manuscritos que preservan el Libro III; vid. RichleR, «Manuscripts of Avicenna's Kanon», pág. 149.

33 Oxford, Bodleian Library, Can. Or. 57 (Nebauer 2102) (en adelante, MS Oxford) fols. 289v-326r. En total se conservan 3 manuscritos que preservan el libro en la versión anónima y que según algunos es muy próxima a la versión de ha-Meatí; vid. Richler, «Manuscripts of Avicenna’s Kanon», pág. 149.

34 Canon Medicinae cum aliis opuscule, Arabice. Roma 1593, págs. 552-596; Avicennae Arabum Medicorum Principis. Canon Medicinae, ex Gerardi Cremonensis uersione. Venecia 1608, vol. II.

35 Por ejemplo, en el MS Munich el fann 20 ocupa los fols. $275 \mathrm{v}-280 \mathrm{r}$, mientras que el fann 21 se encuentra entre los fols. 280r-293v. En la edición árabe, el fann 20 ocupa las páginas 552-567 y el fann 21 las páginas 567-596. Por su lado, la primera sección del Zijrón ocupa los fols. 15v-19v, y la segunda los fols. 19v-24r. 
hebreo incluye algunos capítulos de las dos maqālāt en que se organiza el fann 20 del Canon, dedicadas, respectivamente, a las generalidades de los órganos sexuales masculinos y la erección, y a otras afecciones y estados de dichos órganos, excluyendo la erección. De la primera, el compendiador sintetiza los capítulos sobre la escasez de esperma y la ausencia de deseo sexual, sobre el exceso de deseo sexual, y sobre la erección prolongada sin deseo sexual ${ }^{36}$. De la segunda, extracta los capítulos sobre los apostemas calientes o fríos y gruesos que ocurren en el miembro y provocan picazón, el tratamiento para la sarna que vuelve a afligir el miembro, el tratamiento para el miembro que se mueve involuntariamente, el tumor en los testículos, el tumor hidrópico y la inflamación del escroto, y el tratamiento de la hernia y el colapso del escroto ${ }^{37}$.

La segunda sección del tratado presenta una mayor labor de edición, ya que el autor no solo parece más minucioso en la selección de afecciones que incluye, sino que reorganiza la estructura de la exposición de uno de los trastornos que trata, como veremos más adelante. El fann 21 se organiza en cuatro maqālāt; de la primera, que trata sobre fertilidad y concepción, el Zijrón omite todos los apartados sobre la concepción y el embrión para interesarse brevemente por las causas de la esterilidad entre las que, a pesar de que el capítulo está incluido en una sección sobre mujeres, se encuentran algunas que no las responsabiliza solamente a ellas ${ }^{38}$. La elección de este único tema refleja una preocupación fundamental de los autores médicos en cualquiera de las lenguas medievales, que fue a su vez una preocupación central en la vida de las comunidades judías, árabes y cristianas a lo largo de la Edad Media: la esterilidad, como contrapartida de la fertilidad.

\footnotetext{
${ }^{36}$ MS Wellcome, fols. $15 \mathrm{v}-17 \mathrm{r}$.

${ }^{37}$ MS Wellcome, fols. $17 \mathrm{r}-19 \mathrm{v}$.

38 MS Wellcome, fols. 19v-20r.
} 
MS Munich, fol. 282r

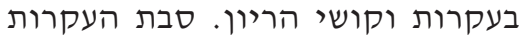

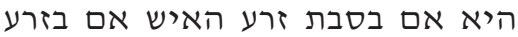

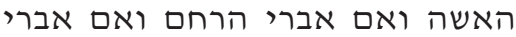

האמה ואם אברי הזרע [...]
\end{abstract}

Sobre la esterilidad y la dificultad para quedarse embarazada. La causa de la esterilidad puede deberse al semen del hombre o al semen de la mujer, o a los órganos del útero o a los del pene, o a los órganos del semen $[\ldots]^{39}$.
MS Wellcome, fol. 19v

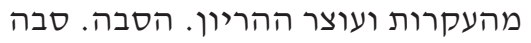

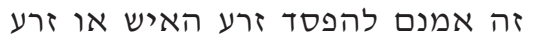

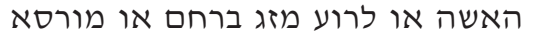
קשה או חולי כליי או לקוצר לרוע האמה.

Sobre la esterilidad y lo que impide el embarazo. La causa puede ser la corrupción del semen del hombre o del semen de la mujer, o un temperamento maligno en el útero, o un apostema duro, o una afección en los órganos [reproductivos], o un pene corto $^{40}$.

En este primer apartado, también se hace una referencia a la tradición judía, al conectar la aplicación de un tratamiento para facilitar la concepción con las leyes de pureza ritual, que no tiene paralelo en las otras versiones hebreas:

${ }^{39}$ Mi traducción al español. Se corresponde con el fann 21, maqala I, capítulo 8 de Canon; $c f$. Max Meyerhoff y D. JoAnnides, La Gynécologie et l'obstétrique chez Aviccene (Ibn Sīnā) et leurs rapports avec celles des grecs (El Cairo, 1938) pág. 24, y Canon medicinae, vol. II, pág. 925.

${ }^{40}$ Mi traducción al español; $c f$. BARKaI, A History of Jewish Gynaecological Texts, págs. 114 y 121, en hebreo e inglés, respectivamente. 
MS Munich, fol. 283r
MS Wellcome, fol. 20r

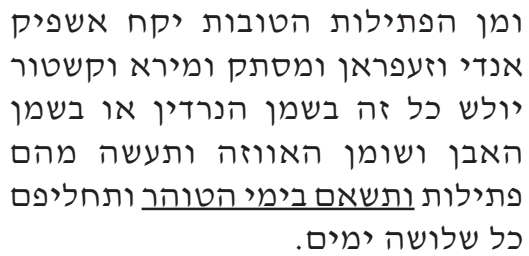

Sobre los pesarios buenos [para quedarse embarazada]. Toma espicanardo, azafrán, almástiga, mirra y castóreo, amásalos bien con aceite de nardo o de aceite de ben y grasa de ganso, y haz pesarios que ella deberá llevar durante los días de su purificación, cambiándolos cada tres días $^{42}$. serapino, $d l y$, aceite de
biándolo cada tres días ${ }^{41}$.

De la segunda maqāla, sobre el embarazo y el parto, el tratado hebreo incluye una sección dedicada a la mola y otra a la atención del parto detenido u obstruido y a la extracción del feto muerto ${ }^{43}$. La mola es una afección que crea en las mujeres la falsa impresión de estar embarazadas, al llevar aparejados con frecuencia los síntomas de la preñez. Las causas de la enfermedad que recopila el Zijrón son diversas (apostemas, hidropesía, agua maligna, etc.) y entre ellas se encuentra una relacionada con el debate medieval sobre la existencia de semen femenino. Los autores judíos medievales, seguramente debido a que el judaísmo reconocía la emisión de esperma por parte las mujeres ${ }^{44}$, parecen haberse adherido de forma mayoritaria a la teoría de origen hipocrático que explicaba que

${ }^{41}$ Mi traducción al español.

42 Mi traducción al español; cf. BARKaI, A History of Jewish Gynaecological Texts, págs. 115 y 133, en hebreo e inglés, respectivamente.

${ }^{43}$ MS Wellcome, fols. 20r-21v.

${ }^{44}$ Talmud de Babilonia, Tratado Niddah 31a. 
hombres y mujeres emiten semen, contribuyendo de la misma forma a la generación del feto. Como muchas otras teorías hipocráticas, ésta había sido adaptada por Galeno, quien consideraba el semen femenino menos perfecto que el masculino. Esta tendencia a minusvalorar la aportación del semen femenino a la generación del feto se va a consolidar conforme avanza la Edad Media, con el triunfo del aristotelismo, ya que el filósofo griego había rechazado expresamente esta teoría y había afirmado que las mujeres aportan sólo "materia", mientras que los hombres aportan "forma" 45 . La influencia de la filosofía de Aristóteles va a producir una transformación en la forma en que muchos autores medievales entienden la generación, lo que dará lugar a una posición ambigua por parte de muchos filósofos y científicos judíos, como Maimónides y sus seguidores, que se debatirán entre la tradición judía y el pensamiento filosófico ${ }^{46}$.

En este caso, el compendiador del Zijrón atribuye la formación de la mola a una de las dos etiologías propuestas por Ibn Sīnā, al considerar que ésta se produce cuando el esperma de la mujer no se ha mezclado con el del hombre durante el coito, por lo que este ha perdido la fuerza generativa y no puede aportarle la forma ${ }^{47}$. La consecuencia es la formación, y subsiguiente expulsión, de un trozo de carne amorfa.

45 Aristóteles, Generation of Animals, trad. Arthur Leslie Peck (London: Heinemann - Cambridge, Mass.: Harvard University Press, 1943) 729a34-730a35; Sharon Faye Koren, «Kabbalistic Physiology: Isaac the Blind, Nahmanides, and Moses de Leon on Menstruation», AJS Review 28:2 (2004) págs. 317-339: 327.

46 Caballero Navas, «Maimonides' Contribution», pág. 37.

47 Sobre la etiología de la mola según la literatura médica medieval, veáse Paloma Moral de Calatrava, «El aborto en la literatura médica castellana del siglo XVI», $D y$ namis 26 (2006) págs. 39-68: 47-57. 
MS Munich, fol. 287v

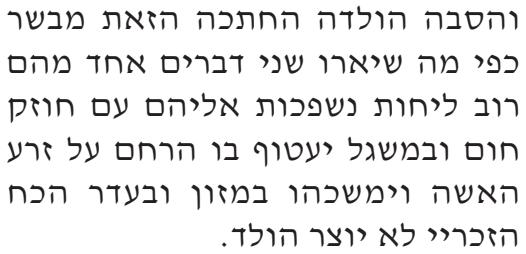

El motivo de que sea engendrado ese trozo de carne se debe, según se verá, a dos cosas. Una de ellas es la abundancia de humores que se derrama de ellas con la fuerza del calor, y [la otra] que durante el coito el útero envuelva el semen de la mujer y atraiga hacia él el alimento, y al faltar la fuerza masculina no se forme el feto ${ }^{48}$.
MS Wellcome, fol. 20v

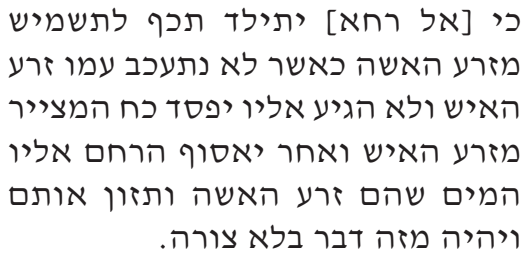

Pues [la mola] se forma inmediatamente tras el coito cuando el esperma de la mujer no se ha mezclado con el esperma del hombre, de tal forma que éste pierde la fuerza generativa. A continuación se deposita en el útero el líquido que es el esperma de la mujer, que al ser nutrido se convierte en una cosa sin forma ${ }^{49}$.

El compendiador del tratado hebreo también acomoda estas teorías al judaísmo, al recurrir a la autoridad rabínica para evocar las posibles apariencias o características que puede poseer dicho trozo de carne sin forma ${ }^{50}$. Con el fin de sustentar la veracidad de los nacimientos anómalos o monstruosos provocados por la afección, y quizá para ilustrar la taxonomía rabínica, también recurre a la autoridad de comadronas y otras mujeres "virtuosas" que le han aportado ejemplos tomados de su experiencia en el espacio del parto,

${ }^{48}$ Mi traducción al español. Correspondencia con fann 21, maqala II, capítulo 19 del Canon; $c f$. Meyerhoff y Jonnnides, La Gynécologie, págs. 41-42, y Canon medicinae, vol. II, pág. 931.

49 Mi traducción al español; $c f$. BARKAI, A History of Jewish Gynaecological Texts, págs. 116 y 133, en hebreo e inglés, respectivamente.

${ }^{50}$ El Talmud de Babilonia, Nidá, 21a-24b, recoge el debate rabínico sobre la impureza de las mujeres que han abortado o dado a luz cuerpos o elementos extraños o monstruosos tras un embarazo anómalo. 


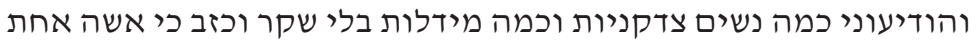

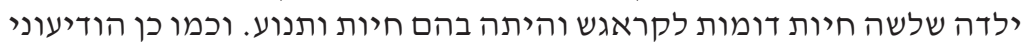

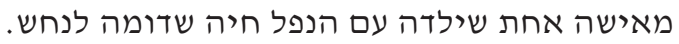

Me informaron algunas mujeres virtuosas y comadronas sin mentiras ni falsedades que una mujer dio a luz tres criaturas parecidas a cuadrúpedos, que estaban vivas y se movían. De la misma forma, me informaron sobre una mujer que alumbró junto a un feto muerto una criatura parecida a una serpiente ${ }^{51}$.

En este fragmento también se aprecia un indicio de que el compendiador posee experiencia clínica, a la que hace referencia en algún otro pasaje del tratado ${ }^{52}$, y en el transcurso de la cual parece haber mantenido relación o haber interactuado con comadronas o mujeres que se dedican al cuidado de la salud. Aunque el estudio de la práctica médica femenina excede los límites de este artículo, me parece importante señalar el interés que tiene el análisis del tratado para conocer la visión de un autor médico, quien probablemente también practicaba medicina, sobre la práctica sanitaria de sus contemporáneas.

Es significativo que de los numerosos capítulos que dedica Ibn Sīnā en esta segunda maqāla a la gestión del embarazo y el parto, el compendiador del Zijrón haya recogido solo una muestra de los que tratan el parto detenido u obstruido y la extracción del feto muerto ${ }^{53}$. En el apartado se exponen las distintas causas que pueden dificultar el parto, que pueden derivarse de la propia parturienta (que esté asustada, o sea demasiado delgada o demasiado gruesa), del feto (que sea demasiado pequeño o demasiado grande, o tenga una enfermedad), o de causas externas, como frío excesivo. La dificultad en el parto ponía en riesgo la vida de la madre y del feto, y a prueba la pericia de las comadronas.

${ }^{51}$ MS Wellcome, fol. 20v. Mi traducción al español; $c f$. BARKaI, A History of Jewish Gynaecological Texts, págs. 116 y 134, en hebreo e inglés, respectivamente.

Ahora recodaremos los medicamentos que he probado y he encontrado beneficiosos en gran medida para esta enfermedad». MS Wellcome, fols. 20r-20v; cf. BARKaI, A History of Jewish Gynaecological Texts, págs. 115 y 132, en hebreo e inglés, respectivamente.

${ }^{53}$ MS Wellcome, fols. 20v-21v. 
MS Munich, fol. 288v

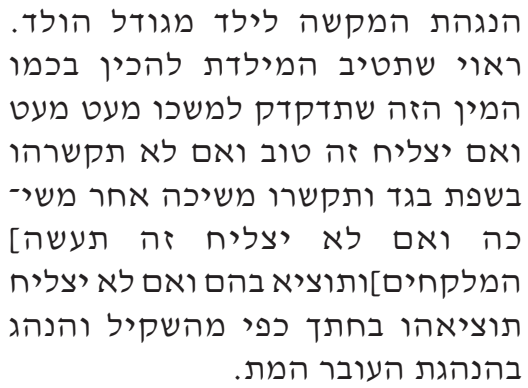

Tratamiento para la dificultad en dar a luz debido al tamaño del feto. Es conveniente que la comadrona compruebe y prepare cómo debe proceder; ha de tirar de él suavemente, poco a poco; si consigue [sacarlo], bien; si no, que le ate una tira de tela $\mathrm{y}$ [tire] un tirón tras tirón; si no consigue [sacarlo], que tome las tenazas y lo saque con ellas; y si no lo consigue, que lo saque con un corte según se acostumbra en el procedimiento para el feto muerto ${ }^{54}$.
MS Wellcome, fol. 21r

ואם תהיה הסבה גודל העובר יתחייב

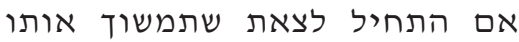

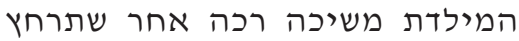
המקום במים הפושרין ולפעמיכה אים בגרי שתי דק ותמשוך מעט מעט עד שיצא ואם ואים ולפוים בגודי לא יחתוך או יוציאואותו כמו שיוציאו מעי מיאי

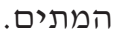

Si la causa [de la obstrucción del parto] es el tamaño del feto, cuando empiece a asomar la comadrona debe tirar de él suavemente tras lavar el sitio con agua templada, y a veces con azafrán machacado. Tiene que tirar poco a poco hasta que salga. $\mathrm{Si}$ no sale, que lo corte [a piezas] o lo saque como se saca a los [fetos] muertos $^{55}$.

La tercera y cuarta maqāla del Canon de la medicina están dedicadas, respectivamente, a las enfermedades del útero. Curiosamente, el autor o compendiador del Zijrón parece no estar interesado en la última parte del fann 21, ya que selecciona una única dolencia, la sofocación uterina provocada por retención de esperma, que a su vez combina con la misma

${ }^{54}$ Mi traducción al castellano. El paralelo se encuentra en el Libro III, fann XXI, maqala II, cap. 28 del Canon de Avicena; $c f$. Meyerhoff y JoAnnides, La Gynécologie, págs. 46-47, y Canon medicinae, vol. II, pág. 942.

55 Mi traducción al castellano. BARKaI, A History of Jewish Gynaecological Texts, págs. 117 y 136, en hebreo e inglés, respectivamente. La práctica de la embriotomía estaba aceptada por el judaísmo, en virtud del principio picúah nefeš, en el que prevalece salvar la vida de la madre, según explica Maimónides en su Mišné Torá, Hilkot Roṣéah 1,9 . 
afección pero con otra etiología -la retención de la menstruación- de la tercera maqāla ${ }^{56}$. Es decir, recoge en un mismo capítulo las diversas casusas de una dolencia que Ibn Sīnā había distribuido en dos maqālāt distintas, precisamente en virtud de su diferente etiología.

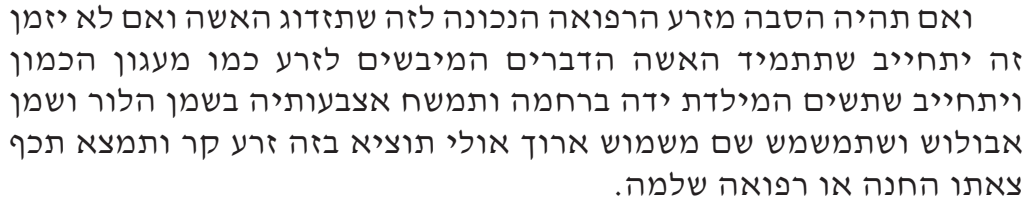

Si la causa [de la sofocación uterina] es el semen, el tratamiento adecuado es que la mujer tenga relaciones sexuales. Si no fuera posible, la mujer debe recurrir a sustancias que sequen el semen, como el electuario de comino. La comadrona debe aplicar su mano al útero de la mujer tras untarse los dedos con aceite de laurel y aceite de ébulos y masajear aquí y allí durante un largo rato. Entonces quizá expulse la mujer semen frío, por lo que se sentirá mejor inmediatamente o se recobrará por completo ${ }^{57}$.

De la tercera maqāla, el compendiador del tratado hebreo ha seleccionado dos dolencias relacionadas con la menorragia y la amenorrea ${ }^{58}$, lo que no es de extrañar teniendo en cuenta la centralidad que ocupa la menstruación en la explicación de la salud y la enfermedad femeninas en la literatura médica medieval ${ }^{59}$.

El estudio preliminar confirma la hipótesis de que el Zijrón no es sino una sinopsis hebrea de una parte del Canon de la medicina de Ibn Sīnā. La correspondencia entre sus dos secciones y algunos capítulos de los funūn 21 y 22 del Libro III del Canon no deja lugar a dudas. Sin embargo, el hecho de que se haya descartado la posibilidad de que el tratado sea una obra "genuinamente" hebrea, como sostenía Barkai, no

${ }^{56}$ MS Wellcome, fols. 21v-22v.

${ }^{57}$ MS Wellcome, fol. 22r. Mi traducción al español; cf. BArKaI, A History of Jewish Gynaecological Texts, págs. 118 y 139, en hebreo e inglés, respectivamente. El paralelo se encuentra en el Libro III, fann XXI, maqāla IV, pág. 18 del Canon de Avicena; $c f$. MeYerhoff y JoAnnides, La Gynécologie, pág. 66, y Canon medicinae, vol. II, pág. 958.

58 MS Wellcome, fols. 22v-24r.

59 Monica Green, The Trotula. A Medieval Compendium of Women's Medicine (Philadelphia: University of Pennsylvania Press, 2001) págs. 19-22. 
invalida su hipótesis sobre la fecha y lugar de composición, que él basaba sobre todo en argumentos lingüísticos ${ }^{60}$, a los que se suman otros de carácter socio-histórico que se expondrán más adelante. Si, teniendo esto en cuenta, asumimos que el Zijrón pudo haber sido compuesto en la Península Ibérica en el paso del siglo XII al XIII, quedaría descartada la posibilidad de que se tratara de una adaptación de una de las traducciones hebreas del Canon conocidas, ya que, que sepamos, no se realizó ninguna hasta finales del siglo XIII ${ }^{61}$. Esta línea de pensamiento nos lleva a reconsiderar la temprana teoría de Steinschneider sobre la traducción del árabe ${ }^{62}$, para sugerir que la sinopsis hebrea pudo haber sido hecha directamente desde dicha lengua. El estudio realizado hasta ahora parece confirmar que no existe relación directa entre el Zijrón y las versiones de Natán ha-Meatí o la del traductor anónimo. Con el fin de apoyar esta teoría, además de los ejemplos presentados en este trabajo, se ofrece a continuación una muestra de los resultados de un cotejo preliminar de la lengua usada por el autor del tratado hebreo, la traducción de Natán ha-Meatí ${ }^{63}$, y la traducción anónima, lo que permite apreciar las diferencias,

\begin{tabular}{|c|c|c|c|}
\hline & Zijrón & Natán ha-Meatí & Anónimo, s. XIV \\
\hline $\begin{array}{l}\text { Ausencia de } \\
\text { deseo sexual }\end{array}$ & ביטול התאוה & חסרון תאות & מעוט התשמיש \\
\hline $\begin{array}{c}\text { Exceso de deseo } \\
\text { sexual }\end{array}$ & יתרון התאוה & ברוב התאוה & בריבוי התאוה \\
\hline Testículos & אשכים & אשכים & ביצים \\
\hline
\end{tabular}

60 BARKaI, A History of Jewish Gynaecological Texts, págs. 68-70.

61 Véase, arriba, nota 24.

62 Véase, arriba, nota 14.

63 Aunque no analiza los mismos capítulos ni los mismos términos, veáse el interesante artículo de Gerrit Bos, «Medical Terminology in the Hebrew Tradition: Nathan ben Eliezer Ha-Me'ati, Glossary to the Hebrew Translation of Ibn Sīnā's Kitāb al-Qānūn fi al-țibb», Revue des études juives 172:3-4 (2013) págs. 305-332; asimismo, Gerrit Bos, Novel Medical and General Hebrew Terminology from the 13th Century. Vol. 4 (Leiden, Brill, 2018). 


\begin{tabular}{|c|c|c|c|}
\hline & Zijrón & Natán ha-Meatí & Anónimo, s. XIV \\
\hline $\begin{array}{l}\text { Sobre la erección } \\
\text { sin deseo sexual }\end{array}$ & רלוב זקיפת & ברוב הקושי לא תאוה & בריבוי הקושי לא תאוה \\
\hline Menstruación & נדות & נדות & וסת \\
\hline $\begin{array}{l}\text { Sobre la esterili- } \\
\text { dad y lo que } \\
\text { impide el embara- } \\
\text { zo }\end{array}$ & ועוצר ההריון & בעקרות וקושי & בעוצר והעקרה \\
\hline Mola (árabe) & אל רחא & Omite & Omite \\
\hline $\begin{array}{c}\text { Dará a luz un } \\
\text { [trozo] de carne } \\
\text { sin forma }\end{array}$ & תלד בשר בלי & שמלט חתכה בשר צורה לא & חתיכה מין הבשר \\
\hline $\begin{array}{l}\text { Detención del } \\
\text { parto }\end{array}$ & עוצר הלידה & קושי הלידה & בעצירת הלידה \\
\hline $\begin{array}{l}\text { La retención y } \\
\text { disminución de } \\
\text { sangre menstrual }\end{array}$ & התאחות דם ומעוטו & ומעוטר הנדות הנדות & הווסת הנעצר \\
\hline $\begin{array}{c}\text { Sofocación } \\
\text { uterina }\end{array}$ & מחנק הרחם & מחנק הרחם & חניקת הרחם \\
\hline Epilepsia (ar.) & צרע & omite & omite \\
\hline Vena & גיד & עורק & גיד \\
\hline $\begin{array}{l}\text { Sangría de la } \\
\text { [vena] safena }\end{array}$ & $\begin{array}{c}\text { הקזת גיד אל צאפן } \\
\text { הנרא }\end{array}$ & הקזת הצפאן & הזקת מהאל צפין \\
\hline
\end{tabular}

\section{El ZIJRÓN EN EL CONTEXTO CULTURAL Y CIENTÍFICO ARABIZADO DE LA CASTILla DE LOS SIGLOS XII-XIII}

Solo un siglo después de que Toledo fuera conquistada por los cristianos, hacia 1187, el Canon de la medicina fue traducido al latín bajo la dirección de Gerardo de Cremona en el marco de un proyecto de importancia decisiva para la transmisión de la ciencia greco-árabe a la 
Europa cristiana ${ }^{64}$. Esta traducción, plausiblemente llevada a cabo de forma colaborativa, como otras tantas traducciones realizadas en esa época y contexto, atestigua la circulación del Canon en árabe en el mismo contexto en el que el Zijrón parece haber sido compuesto. La existencia de un manuscrito árabe que contiene el Libro III del Canon, producido en Castilla alrededor del 1100-1150 y que incluye anotaciones marginales que transliteran terminología árabe en hebreo, realizadas en escritura sefardí posiblemente del siglo XIII, se convierte en un testigo excepcional del uso de la obra en árabe por los judíos castellanos ${ }^{65}$. Aunque el manuscrito y sus anotaciones marginales esperan aún a ser estudiadas, su sola existencia respalda, de un lado, la conocida teoría sobre el consumo de literatura médica en árabe por parte de los médicos judíos castellanos hasta varios siglos después de la conquista castellana ${ }^{66}$; de otro, la posibilidad de que un médico judío arabófono tuviera acceso a la obra en Castilla en las fechas sugeridas por Barkai y llevara a cabo una sinopsis en hebreo de los capítulos que le interesaban.

Como ya se ha señalado, los judíos siguieron produciendo y consumiendo ciencia en árabe - especialmente medicina- en tierras de Castilla hasta finales del siglo Xv. No solamente lo atestiguan el consumo y posesión de manuscritos en árabe a los que me he referido con anterio-

${ }^{64}$ Charles Burnett, «The Coherence of the Arabic-Latin Translation Program in Toledo in the Twelfth Century», Science in Context 14:1-2 (2001) págs. 249-288; Dag Nikolaus Hasse, «The Social Conditions of the Arabic-(Hebrew)Latin Translation Movements in Medieval Spain and in the Renaissance», en Wissen über Grenzen: Arabisches Wissen und lateinisches Mittelalter, eds. Andreas Speer y Lydia Wegener (= Miscellanea Mediaevalia 33 [Berlin: de Gruyter, 2006]) págs. 68-86, y van Koningsveld, «Andalusian-Arabic Manuscripts from Christian Spain», pág. 77.

65 Rare Book and Manuscript Library University of Pennsylvania, Ms UPenn LJS 446; cf. Crofton Black, (ed.), Transformation of Knowledge, Early manuscripts from the collection of Lawrence J. Schoenberg (Londres, Paul Holberton, 2006) pág. 80. http:// sceti.library.upenn.edu/ljscatalog/index.html. Último acceso, 20/05/2019.

66 VAN Koningsveld («Andalusian-Arabic Manuscripts from Christian Spain», págs. 90 y 100-110 [nos. 71,78, 82, 86, 90, 91 y 92]) menciona siete manuscritos árabes con glosas hebreas o judeo-árabes entre un grupo más numeroso de manuscritos árabes que pertenecieron o fueron comisionados por judíos en los territorios cristianos de la Península Ibérica. 
ridad $^{67}$, sino al hecho de que casi dos siglos después de que el Canon fuese traducido al latín en Toledo, un médico judío aún no identificado escribiera en árabe el Kitāb al-țibb al-qaštālà al-malūkī (Libro de medicina castellana regia) ${ }^{68}$. Como era de esperar, al ofrecer una lista de autores y textos médicos necesarios para la formación teórica y práctica de los médicos judíos de su tiempo que circulaban en Castilla, el autor menciona el Canon de Ibn Sīnā, junto a Galeno, el al-Hāwwī de al-Rāzī, el Taṣrî̉ de al-Zahrāwī y el Kāmil aș-ṣinna ${ }^{\prime} a$ de al-Maŷūsī ${ }^{69}$. Como ya afirmara Luis García Ballester hace más de dos décadas, los textos árabes proporcionaron a los médicos judíos castellanos conocimiento médico teórico y práctico, y contribuyeron a su cohesión social ${ }^{70}$.

Volviendo al Zijrón, la decisión de su desconocido compendiador de extractar precisamente los capítulos dedicados a las enfermedades de los órganos de la reproducción es, en mi opinión, indicio de un cambio en el modelo de apropiación y difusión de conocimiento médico y ginecológico que irá transformando gradualmente la forma en que se transmite el saber escrito sobre la atención y el cuidado de la salud femenina, que pasa de estar integrado en una obra de carácter general a circular de

67 Véase, arriba, nota 23. El trabajo de van Koningsveld («Andalusian-Arabic Manuscripts from Christian Spain», págs. 89-90 y 95-110 [apéndice]) aporta evidencias de la existencia de tres «bibliotecas» judías entre 1182 y 1227 en Toledo que contaban entre sus fondos con importantes manuscritos médicos árabes como la Materia medica de Dioscórides, el tratado dedicado a cirugía del Tașrîf de al-Zahrāwī, el Kāmil aṣ-șinnā'a de al-Maŷūsī, el al-Hiāwī de al-Razī, etc.

${ }^{68}$ Edición y traducción castellana: Concepción VÁzquez DE Benito, «El Kitāb al-țibb al-qašțālì al-malūk̄̄ (Libro de medicina castellana regia) (ca. 1312)», en Ciencias de la Naturaleza en al-Andalus. Textos y Estudios, eds. Expiración García SÁncheZ y Camilo Álvarez de Morales, vol. VII (Granada: CSIC, 2004) págs. 11-107; VÁzquez de Benito, «Medicina castellana regia», en Ciencias de la Naturaleza en al-Andalus. Textos y Estudios, ed. Camilo Álvarez de Morales, vol. VI (Granada: CSIC, 2001) págs. 11-91.

69 VÁzQuez de Benito, «El Kitāb al-țibb al-qašțālī», pág. 42 [fol. 7r] y «Medicina castellana regia», pág. 25.

${ }^{70}$ Luis García Ballester, «A Marginal Learned Medical World: Jewish, Muslim and Christian Medical Practitioners, and the Use of Arabic Medical Sources in the Late Medieval Spain», en Practical Medicine from Salerno to the Black Death. eds. Luis García Ballester, Roger French, Jon Arrizabalaga y Andrew Cunningham (cambridge: Cambridge University Press, 1994) págs. 353-394: 376-390, y Luis GARCíA Ballester, La búsqueda de la salud. Sanadores y enfermos en la España medieval (Barcelona: Península, 2001) págs. 454-472. 
forma independiente, tal y como ocurría en la tradición médica latina ${ }^{71}$. Aunque en un contexto diferente, este tipo de transformación es similar a la que hace posible que todo el material sobre salud femenina recogido en enciclopedias médicas islámicas tenga un papel primordial en la transmisión al occidente latino medieval de las teorías ginecológicas de la antigüedad (greco-latinas y bizantinas), de las que previamente se habían apropiado, adaptándolas, los filósofos y autores médicos árabes ${ }^{72}$. Es el caso, especialmente, de las obras de al-Maŷūsī e Ibn alŶazzār, que tendrán un peso significativo en la formación de la corriente de literatura ginecológica que se difundió desde Salerno a partir del siglo XII en latín y en otras lenguas medievales, y cuyo máximo exponente sería el compendio formado por tres obras que circuló atribuido a Trota of Salerno ${ }^{73}$. Junto a ello, la creación de un tratado de ginecología independiente a partir de un fragmento de la traducción latina de la obra de al-Maŷūsī por Constantino el Africano ${ }^{74}$ corrobora la transformación de un modelo de difusión que está íntimamente asociado a los procesos de traducción de la Edad Media.

En estos ejemplos, los materiales extractados para formar parte de una nueva obra, o convertirse en un tratado independiente, fueron tomados de las versiones latinas de textos árabes. Podemos encontrar ejemplos de este mismo modelo de apropiación en el corpus de medicina hebrea, en el que el tratado Licuté Rabenu Mošé be-inyané véset veherayón (Compilación de nuestro maestro Moisés sobre menstruación y embarazo) no es sino el capítulo xvi de los Aforismos médicos de Maimónides (Kitāb al-fușūl fì al-țibb, 1185), escrito originalmente en árabe y dedicado a la anatomía, fisiología y enfermedades de las mujeres, que fue separado del resto de la obra y puesto en circulación en algún mo-

71 Caballero Navas, «The Genesis of Medieval Hebrew Gynaecology».

72 Véase, arriba, nota 19.

73 Monica Green, «The 'Development' of the Trotula», Revue d'Historie des Textes 26 (1996) págs. 119-203; Green, The Trotula. Sobre su traducción la hebreo, véase, arriba, nota 8.

${ }^{74}$ Sobre la circulación en latín de algunos capítulos de la Teorica del Pategni como tratado independiente, véase Monica GrEEn, «The De Genecia attributed to Constantine the African», Speculum 62:2 (1987) págs. 299-323. 
mento tras su traducción al hebreo por Zerahiah Šealtiel Ḥen en1277 75 . Como han señalado algunos autores, el movimiento de traducción del árabe al hebreo, que había nacido a mediados del siglo XII, no solo implicaba la realización de traducciones directas, sino una gran variedad de formas literarias entre las que se encuentran la composición de enciclopedias que compilaban y sintetizaban en hebreo la filosofía y la ciencia árabes para quienes no están instruidos en ellas, y la redacción de obras monográficas, escritas en ambos casos por judíos arabófonos ${ }^{76}$. Este modelo de traducción del árabe al hebreo se acomoda a la labor realizada por el desconocido compendiador del Zijrón, quien selecciona y sintetiza partes del Canon de Ibn Sīnā para crear un tratado monográfico independiente. Aunque no parece existir una relación causal entre el movimiento de traducción del árabe al latín y el del árabe al hebreo ${ }^{77}$, es evidente que el contexto de traducción de la Castilla multicultural y arabizada de finales del siglo XII y principios del XIII se convirtió en el marco apropiado para la producción del tratado. No obstante, no podemos conocer la motivación que se esconde tras la composición del tratado hebreo, es decir, si su plasmación formaba parte de un interés específico o de un programa intelectual más amplio.

El hecho de que se haya conservado en una única copia manuscrita del siglo Xv nos informa de que tuvo que tener cierta circulación durante los dos siglos anteriores, es decir, desde que fuera compuesto hasta que se realizó esta copia, aunque desconocemos cómo fue su difusión. Tampoco sabemos si sus contemporáneos o las generaciones posteriores que lo conocieron fueron conscientes de su vinculación con el Canon, ni si algunos autores médicos que incluyeron en sus obras remedios de la obra de Ibn Sīnā pudieron haberlos tomado de esta versión hebrea. De lo que sí tenemos constancia es de la continuidad del interés en los capítulos sobre enfermedades de los órganos reproductivos del Canon de la medicina en la Península Ibérica. Ron Barkai señalaba en 1998 que el $\mathrm{Zi}$ -

75 Véase Caballero Navas, «Maimonides' Contribution», pág. 41.

76 Gad Freudenthal y Ruth Glasner, «Patterns of Medieval Translation Movements», en De l'Antiquité tardive au moyen âge, eds. Elisa CODA y Cecilia MarTini Bonadeo (Paris: Vrin, 2014) págs. 245-252: 246-247.

77 Gad Freudenthal, «Arabic into Hebrew. The Emergence of the Translation Movement in Twelfth-Century Provence and Jewish-Christian Polemics», pág. 128. 
jrón parece guardar relación con los capítulos sobre enfermedades genitales masculinas y femeninas de dos importantes obras médicas escritas con posterioridad en árabe y en castellano, respectivamente, de las que podría ser la fuente: el 'Amal man tabba li-man habba (Tratado de patología general y especial) del granadino Ibn al-Jatib (1313-1374), y el Tratado de patología general, obra anónima castellana del siglo XIV ${ }^{78}$. Un nuevo estudio podría determinar si ambas obras se inspiraron o no en el tratado hebreo, si bien, en mi opinión, la lengua en que está escrito limita de alguna manera las posibilidades, aunque no las elimine. En todo caso, una vez identificada la fuente del Zijrón, podemos apuntar que los funūn 20 y 21 del Canon de la medicina constituyen el punto de intersección entre las tres obras, independientemente de la forma en que su influencia llegara a cada una de ellas.

\section{EpÍLOGO: LA DIFUSIÓN DEL ZIJRÓN EN EL SIGLO XV}

Las obras de las que se ha conservado una única copia manuscrita parecen evidenciar el éxito escaso de que gozaron en su época. No obstante, aún contando con las vicisitudes de la transmisión textual, a veces olvidamos que la producción de manuscritos era cara y requería mucha inversión de tiempo y esfuerzo como para que se copiaran manuscritos que no habían despertado interés o no tenían un público. En este caso, la sola circunstancia de que exista una copia realizada más de dos siglos después de que se compusiera el tratado demuestra que hubo copias intermedias que no se han conservado o no han sido identificadas. Asimismo, al margen del número de copias que existieron o nos hayan llegado, los manuscritos tienen interés en sí mismos y pueden aportar mucha información si les hacemos las preguntas adecuadas.

El único manuscrito del Zijrón que se conserva, o que ha sido identificado hasta ahora, forma parte de un códice que preserva solo cuatro obras breves: la primera sobre las hemorroides, las otras tres sobre gi-

78 BARKaI, A History of Jewish Gynaecological Texts, págs. 70-71; vid. Concepción VÁzquez de Benito y María Teresa Herrera, «Dos capítulos ginecológicos: árabe y castellano», Asclepio 33 (1981) págs. 183-241, y María Teresa Herrera, (ed.), Tratado de patología general (Madison: Hispanic Seminary of Medieval Studies, 1987). 
necología, lo que tiene cierta coherencia ${ }^{79}$. Curiosamente, los tres tratados ginecológicos pertenecen a la primera etapa de la formación del corpus hebreo sobre salud femenina; dos fueron traducidas del latín por Doeg ha-Edomí -Séfer ha-em el-Galinus y Séfer ha-tolédet- y provienen de una de las tradiciones de ginecología más apreciadas de la antigüedad (la Ginecología de Sorano de Éfeso en la adaptación latina de Muscio); y la tercera es un epítome de una parte de la obra más célebre de la medicina islámica medieval. El reconocimiento duradero del que todas ellas gozaron a lo largo de la Edad Media, y aún después, podría explicar el interés del copista en formar un códice casi monográfico. Aún así, éstos no son los únicos manuscritos que nos han llegado gracias principalmente a copias tardías, ya que la mayoría de las versiones conservadas de los tratados que componen el corpus hebreo de ginecología provienen de los siglos XIV, XV y XVI ${ }^{80}$.

Como ha puesto de relieve Monica Green en relación con la literatura y la práctica médicas sobre salud femenina, a partir del siglo XIII surge un nuevo interés por parte de los médicos, eruditos o no, por la ginecología y la obstetricia, especialmente por la cirugía obstétrica, que se va a afianzar hacia el final de la Edad Media ${ }^{81}$. Para Green, la circulación en latín y en hebreo del extenso tratado dedicado a la cirugía del Kitab

79 Véase, arriba, nota 9.

${ }^{80}$ Por ejemplo Séfer ha-tolédet se conserva en otros tres manuscritos del siglo XV (F441, F447 y F1913), Terufot la-herayón en dos de los siglos XIV y XVI (F19949 y F19956), Séfer ahavat našim en uno del siglo xv (F17835), y Licuté Rabenu Mošé beinyané véset ve-herayón en dos del siglo XIV (F.13907 y F19948). Las referencias entre paréntesis se corresponden con los números de registro del catálogo en línea del Instituto de Manuscritos Microfilmados de la Biblioteca Nacional y Universitaria de Israel, en Jerusalén. Las fechas tardías de copia son la tónica general en el corpus hebreo de ginecología, según los resultados preliminares de un estudio en curso sobre la producción y difusión de textos y manuscritos sobre salud femenina en el contexto de la producción textual científica y médica hebrea de la Europa medieval.

81 Monica Green, Making Women's Medicine Masculine. The Rise of Male Authority in Pre-Modern Gynaecology (Oxford: Oxford University Press, 2008) págs. 91-111, $\mathrm{y}$ «Moving from Philology to Social History of Medicine: The Circulation and Uses of Albucasis's Latin Surgery in the Middle Ages», en Between Texts and Patients: The Medical Enterprise in Medieval and Early Modern Europe, eds. Florence Eliza GLazE y Brian NANCE (= Micrologus' Library 39 [Firenze: SISMEL, Edizioni del Galluzo, 2011]) págs. 331-372. 
al-tașrīf li-man 'ajiza 'an al-ta'līf (Libro de la disposición médica para aquéllos que no son capaces de saberlo por sí mismos) de al-Zahrāwī (m. 1013), que dedica un apartado importante a la cirugía obstétrica, ilustrado por diversos instrumentos obstétricos ideados por él, demuestra la atracción que los cirujanos sienten hacia un tipo de conocimiento que les da acceso al cuerpo de las mujeres ${ }^{82}$. Si al-Zahrāwī, conocido en la tradición latina como Abulcasis, es la mayor autoridad en obstetricia, otros autores de la antigüedad y la Edad Media también incluyeron explicaciones, aunque de menor extensión, sobre la atención quirúrgica al parto en los capítulos de sus obras dedicadas a las mujeres. Entre ellos destacan la adaptación latina de Muscio de la Ginecología de Sorano de Éfeso, algunos capítulos de la cirugía de al-Maŷūsī (capítulo IX de su Practica) y la breve descripción sobre instrumentos quirúrgicos usados en el parto difícil incluida en el Libro III, fann 21, maqāla 2 (capítulos 25-29) del Canon de Ibn Sīnā ${ }^{83}$.

Precisamente parte de estas obras están representadas en el códice del siglo XV que ha preservado la copia existente del Zijrón, y con él los capítulos obstétricos del Canon la de medicina. Este códice no es el único que evidencia que el corpus hebreo de ginecología refleja una tendencia análoga a la que manifiesta la tradición latina en la baja Edad Media al favorecer obras que incluyen cirugía ginecológica y obstétrica. El Kitab al-tașrīf de al-Zahrāwī fue traducido del árabe al hebreo en Marsella entre 1254 y 1260 por Šem Tov ben Isaac, quien lo tituló Séfer ha-Šimmúšs. Se han conservado tres traducciones más del árabe y una del latín, realizadas en los siglos XIII, XIV y XV, atribuidas a distintos traductores, aunque solo existe certeza de que la traducción latina se debe a Bonafus Bonfil Astruc ${ }^{84}$. Existen evidencias de que la versión de

82 Green, «Moving from Philology to Social History of Medicine».

83 Green, «Moving from Philology to Social History of Medicine», pág. 357, y Monica Green y Daniel Lord Smail, «The trial of Floreta d'Ays (1403): Jews, Christians, and obstetrics in later medieval Marseille», Journal of Medieval History 34:2 (2008) págs. 185-211: 196-197. Véase también Meyerhoff y JoAnnides, La Gynécologie, págs. 45-47.

${ }^{84}$ Gerrit Bos, «Medical Terminology in the Hebrew Tradition, Shem Tov ben Isaac, Sefer ha-Shimmush, Book 30», Journal of Semitic Studies 55:1 (2010) págs. 53-101; Eduard Feliu y Jon Arrizabalaga, (trads.), «El próleg de Semtov ben Issac, 'el Tortosí,' a la seva traducció hebrea del 'Tasrif' d'Abu-1- Qasim al-Zahrawi», Tamid 3 (2001-2002) 
Šem Tov ben Isaac circuló en el sur de Francia durante el siglo XIV ${ }^{85}$, y quizá en el siglo Xv, aunque la fuente -un inventario post-morten- no permite dilucidar ni la lengua en que está escrita ni de qué versión de la obra se trata. Solo nos informa de que el médico judío Astruc de Sestiers de Aix, que murió en 1439, poseía entre los 36 volúmenes de su magnífica biblioteca médica el Libro 30 (dedicado a la cirugía) de Abulcazi ${ }^{86}$. Significativamente, también tenía en posesión una copia del Libro III del Canon de Ibn Sīnā ${ }^{87}$. De la traducción de Šem Tov se conserva un único manuscrito que haya preservado el Libro 30, producido en los siglos XIV-XV en la Península Ibérica, que acompaña el texto de magníficas ilustraciones de instrumentos quirúrgicos, incluidos artefactos para uso ginecológico y obstétrico ${ }^{88}$.

Otro texto relevante para esta discusión es Mi-coši ha-leda (Sobre las dificultades del parto), un capítulo breve, probablemente desgajado de una obra hebrea más amplia, que trata sobre las causas, síntomas y gestión de los partos difíciles ${ }^{89}$. Se conserva en dos manuscritos de los siglos XIV y XV, respectivamente, el segundo de los cuales incluye las dieciséis figuras de fetus in utero ${ }^{90}$, unos diagramas que representaban

págs. 65-95, y ZoNTA, «Medieval Hebrew Translations of Philosophical and Scientific Texts», págs. 32, 38-39, 46 y 65.

85 Joseph Shatzmiller, «Livres médicaux et éducation médicale: À propos d'un contrat de Marseille in 1306», Medieval Studies 42 (1980) págs. 463-470; GreEn, «Moving from Philology», pág. 338.

86 Danièle IANCu-Agou, «L'inventaire de la bibliothèque et du mobilier d'un médecin juif d'Aix au milieu du xve siècle», Revue des Etudes Juives 134 (1975) págs. 4780 , item 154. Este valioso inventario ha llegado a mi conocimiento gracias a la generosidad de Monica Green, quien ha compartido a través de su página del Portal Academia. edu el material de la conferencia y workshop «Reconstructing Medieval Medical Libraries: Between the Codex and the Computer», que impartió en la Universidad de Harvard en febrero de 2015. Green sugiere una corrección a la interpretación incorrecta de la obra por Iancu-Agou, pág. 7.

87 IAnCU-Agou, «L'inventaire de la bibliothèque», item 147.

88 Paris, Bibliothèque Nationale, héb. 1163, fols. 201r-239r; $c f$. Bos, «Medical terminology», págs. 62-63. El manuscrito ha sido digitalizado y es accesible a través de la web de Bibliothèque Nationale de Francia.

89 Ron BARKaI, «A Medieval Hebrew Treatise on Obstetrics», Medical History 33 (1989) págs. 96-119.

90 Paris, Bibliothèque Nationale, héb. 1120, fols. $67 \mathrm{v}-70 \mathrm{r}$. 
las distintas posiciones fetales que podían crear dificultades en el parto, y que ilustraban la Ginecología de Sorano de Éfeso y la adaptación de Muscio ${ }^{91}$.

Por último, un estudio reciente ha identificado la existencia de un códice árabe, copiado en Sicilia en 1293, que contiene el texto árabe escrito en caracteres hebreos de los apartados VI-X de la primera parte -sobre los principios teóricos- del Kitāb kāmil de al-Maŷūsīin. El hallazgo confirma que los médicos judíos tuvieron acceso a partes de la obra, entre las que se encuentra la anatomía de los órganos de la reproducción, en Sicilia durante los siglos XIII y XIV ${ }^{93}$.

Sin ánimo de alargar la lista de textos y manuscritos para no exceder los límites de este artículo, se han aportado los ejemplos más significativos que atestiguan el creciente interés de médicos y autores (varones) en la gestión del parto difícil como una nueva área de conocimiento e intervención médica, lo que explica la reproducción del Zijrón y del códice completo en el siglo Xv.

No perdemos de vista que la literatura ginecológica medieval es en general un género masculino, escrito y dirigido mayoritariamente a hombres. Sin embargo, hacia la baja Edad Media se percibe un cambio en la forma en que los médicos se relacionan con ella, pasando de ser transmisores de las tradiciones médicas de la Antigüedad, con escasa relación con la práctica, a mostrar un interés que transformará paulatinamente la ginecología y la obstetricia en especialidades médicas masculinas con el paso a la Edad Moderna ${ }^{94}$. En este contexto, la reproducción y difusión del Zijrón tiene el valor añadido - unido a la selección de los capítulos sobre las dificultades del parto- de presentar la práctica médica de las mujeres como subordinada a la de los médicos (varones).

91 Véronique DASEN, «Becoming Human: From the Embryo to the Newborn Child», en The Oxford Handbook of Childhood and Education in the Classical World, eds. Judith Evans Grubbs y Tim Parkin (Oxford: Oxford University Press, 2013) págs. 17-39: 2425; Valentino Rose, (ed.), Soranus Gynaeciorum vetus traslatio latina (Leipzig: B. G. Teubneri, 1882).

92 Giuseppe Mandalì, «Un codice arabo in caratteri ebraici dalla Trapani degli Abbate (Vat. ebr. 358)», Sefarad 71:1 (2011) págs. 7-24.

93 Véase, arriba, nota 20.

94 Green, Making Women's Medicine Masculine. 
Al igual que en la tradición médica islámica de la que proviene el texto original $^{95}$, también en la tradición médica latina son ellas las encargadas de manipular y palpar el cuerpo femenino, mientras que el médico detenta el conocimiento teórico y la autoridad para decidir qué procedimientos son más adecuados y cuándo administrarlos. Esta forma de identificar la ocupación sanitaria de las mujeres nos revela, además de la visión de los médicos varones de cuál y cómo debía ser la práctica médica femenina, un problema que se fue acentuando a lo largo del proceso en el que las mujeres quedaron excluidas de las categorías profesionales derivadas de la implantación de un nuevo sistema médico legitimado por la institución universitaria ${ }^{96}$.

Sin embargo, a pesar del discurso androcéntrico que representa la actividad de las comadronas (y otras sanadoras) como subsidiaria de la del médico, el Zijrón también reconoce su experiencia y competencia. No solo pone en sus manos todos los procedimientos manuales para ayudar a la parturienta a hacer los movimientos que faciliten la expulsión del feto que viene con dificultad ${ }^{97}$, sino que también reconoce su destreza y autonomía cuando al tratar la retención del feto por mala presentación explica que debe ser la comadrona quien ha de manipularlo de acuerdo con su "sabiduría", utilizando para ello el término hebreo hojmá, mediante el que en la Edad Media también se designa a la "ciencia"98. Es más, como hemos visto en uno de los ejemplos propuestos sobre la afección llamada mola ${ }^{99}$, el texto parece recoger el intercambio de experiencia práctica entre el compendiador del tratado y comadronas y otras mujeres sanadoras.

95 Bos, Ibn Al-Jazzār on Sexual Diseases, pág 51; Peter E. Pormann, «The Art of Medicine. Female Patients and Practitioners in Medieval Islam», The Lancet 373 (2009) págs. 1198-1599.

96 Green, Making Women's Medicine Masculine, y Montserrat CABré y Teresa ORTIZ, Sanadoras, matronas y médicas en Europa, siglos XII-XX (Barcelona: Icaria, 2001) págs. 12-24.

97 BARKaI, A History of Jewish Gynaecological Texts, págs. 116-117 y 135-137, en hebreo e inglés, respectivamente.

98 BARKaI, A History of Jewish Gynaecological Texts, págs. 117 y 136, en hebreo e inglés, respectivamente, y CABALlero Navas, "She Will Give Birth Immeditely», pág. 392.

99 Véase, arriba, nota 51. 


\section{CONCLUSIÓN}

Aunque aún queda mucho trabajo por hacer sobre el Zijrón haholayim ha-hovim be-klé ha-herayón, el estudio preliminar llevado a cabo permite confirmar que éste representa la primera adaptación al hebreo desde el árabe de parte del Canon de la medicina de Ibn Sīnā. El desconocido autor compendió deliberadamente en hebreo algunas secciones y capítulos que le interesaban de la obra, en concreto de los funūn 20 y 21 del Libro III, con el fin de componer y difundir un tratado independiente sobre enfermedades en los órganos sexuales de hombres y mujeres. El estudio de este tratado desde esta nueva perspectiva puede contribuir significativamente a comprender las primeras etapas de la formación del corpus hebreo de ginecología, arrojando luz sobre sus fuentes y evolución en contextos diferentes, así como sobre el nuevo interés que despiertan la ginecología y la obstetricia entre los médicos hacia finales de la Edad Media.

La originalidad del tratado reside sobre todo en que muestra una transformación epistemológica en la forma en que la medicina medieval entiende las enfermedades femeninas y su tratamiento, y en el modo en que el cuerpo femenino y su cuidado son conceptualizados. Asimismo, el texto nos ofrece una mirada a la difusión del Canon en árabe en los territorios cristianos de la Península Ibérica, así como a la transmisión e intercambio de conocimiento médico entre miembros de las distintas religiones. De la misma forma, puede contribuir también a nuestra comprensión de la práctica médica femenina en una sociedad multicultural en las primeras y subsiguientes etapas del proceso de profesionalización de la medicina y la ginecología.

Recibido: 29/10/2018

Aceptado: 23/05/2019 